\title{
Influence of a Storm Surge Barrier's Operation on the Flood Frequency in the Rhine Delta Area
}

\author{
Hua Zhong ${ }^{1, *}$, Peter-Jules van Overloop ${ }^{2}$, Pieter van Gelder ${ }^{1}$ and Ties Rijcken ${ }^{1}$ \\ 1 Department of Hydraulic Engineering, Faculty of Civil Engineering and Geosciences, \\ Delft University of Technology, Stevinweg 1, Delft 2628 CN, The Netherlands; \\ E-Mails: P.H.A.J.M.vanGelder@tudelft.nl (P.G.); T.Rijcken@tudelft.nl (T.R.)
}

2 Department of Water Management, Faculty of Civil Engineering and Geosciences, Delft University of Technology, Stevinweg 1, Delft 2628 CN, The Netherlands; E-Mail: P.J.A.T.M.vanOverloop@tudelft.nl

* Author to whom correspondence should be addressed; E-Mail: Hua.Zhong@tudelft.nl; Tel.: +31-15-2789457; Fax: +31-15-2785124.

Received: 9 April 2012; in revised form: 2 May 2012 / Accepted: 4 May 2012 /

Published: 11 May 2012

\begin{abstract}
The Rhine River Delta is crucial to the Dutch economy. The Maeslant barrier was built in 1997 to protect the Rhine estuary, with the city and port of Rotterdam, from storm surges. This research takes a simple approach to quantify the influence of the Maeslant storm surge barrier on design water levels behind the barrier. The dikes in the area are supposed to be able to withstand these levels. Equal Level Curves approach is used to calculate the Rotterdam water levels by using Rhine discharges and sea water levels as input. Their joint probability function generates the occurrence frequency of a certain combination that will lead to a certain high water level in Rotterdam. The results show that the flood frequency in Rotterdam is reduced effectively with the controlled barrier in current and in future scenarios influenced by climate change. In addition, an investigation of the sensitivity of the operational parameters suggests that there is a negligible influence on the high water level frequency when the decision closing water level for the barrier is set higher due to the benefits of navigation (but not exceeding the design safety level $4 \mathrm{~m} \mathrm{MSL}$ ).
\end{abstract}

Keywords: Rhine-Meuse delta; flood frequency; storm surge barriers; equal level curves; joint probability method; sensitivity analysis 


\section{Introduction}

A delta is a landform that is formed at the mouth of a river where that river flows into an ocean, sea or other water body. Its size ranges from tens to several hundreds of kilometers. Due to the special location regarding trade activities, many deltas become economic centers with a highly dense population. However, they are also vulnerable to flooding, and floods are one of the most dangerous hazards of a delta area. To mitigate the effects of flooding, many manmade structures have been constructed in low-lying delta areas all over the world.

A storm surge barrier is a structure that prevents a storm surge or spring tide from propagating into a river, channel or lake behind the barrier. It is usually a part of a larger flood protection system, which consists of floodwalls, levees and other constructions. In England, the Thames barrier was established at the mouth of Thames River. In the USA, a series of storm surge barriers are under discussion as a possible way to deal with the increasing risks of storm surges in New York City [1]. A primary concern related to a barrier is the question: How much does the barrier reduce the flood risk? This article takes the Maeslant storm surge barrier as an example and evaluates the influence of the storm surge barrier on the flood frequency.

The Maeslant storm surge barrier is located in the mouth of the New Waterway in the Rhine Delta. If flooded, the inundation damage in the delta would be enormous. For example, the 1953 sea flooding caused more than 1,800 casualties, and over 150,000 hectares of land flooded, about 9,000 buildings were demolished and 38,000 buildings damaged, 67 breaches occurred and hundreds of kilometers of dikes were heavily damaged. The total economic loss was estimated at 680-900 million Euros [2]. Afterwards the Dutch government embarked on the 'Delta Project'. Since the first Delta Committee in 1953, the Delta Project has been implemented to achieve the design safety level of the delta. The Maeslant storm surge barrier as its final element was established at the mouth of the New Waterway, 5 kilometers inland from Hook of Holland. Through it, the Rhine River discharges into the North Sea. The Maeslant Barrier is always open to facilitate an open connection to the port of Rotterdam and is only closed during high storm surges.

The city of Rotterdam is commonly taken as the reference point in the flood frequency analysis because of its important economic role. Van Dantzig [3] studied the design safety level from an economical, statistical and also from a physical point of view. The design safety level was based on the statistical analysis of historical observations and an economical optimization. According to the Dutch law, the design safety level is 1:10,000 years for Rotterdam. This means that the dikes have to withstand hydraulic conditions with an exceedance probability of 1:10,000 per year. Whether a flood will really occur under these conditions, depends on the state of the dikes, which have many uncertainties. For ease of use, from now on we will call this exceedance probability the flood frequency. In this case the flood frequency analysis is only based on the water level, since overtopping due to extreme water levels is considered to be the most dangerous mechanism for flooding in the delta [4]. Van der Made [5] assessed the frequency of the transitional water level influenced by the combination of Rhine flow and North Sea level. However, due to the construction of the Maeslant Barrier the influence of the combination on the local water stages along the river has changed. This makes it necessary to re-assess the flood frequency under the influence of the barrier. 
In the assessment, annual maximum North Sea levels and their corresponding Rhine flows are selected. Although a peaks over threshold (POT) assessment would have been better as it could offer more extreme North Sea level events, considering a 100 year long annual maximum (AM) assessment avoids possible inhomogeneities in the data. The combination of extreme Rhine flow and its corresponding sea level is excluded, as the water level at Rotterdam is mostly influenced by the North Sea level. This assumption will be illustrated later. Because of lack of data, the possibility of the occurrence of simultaneously extreme North Sea level and Rhine flow is hard to estimate. Van der Made [5] commented that these were independent by comparing the frequency of Rhine flows occurring simultaneously with extreme storm surges, with the frequency of Rhine flows occurring regardless of the size of surge. These two frequencies were found not to be significantly different. M. Jorigny, et al. [6] also commented that these were independent by investigating the Pearson's coefficient between extreme wind set-ups and their corresponding Rhine flows. In this study the dependence will be assessed again with new additional data.

The joint probability method will be used to assess the frequency of the transitional water level. Here, with the help of the simplified hydraulic functions - Equal Level Curves [7] - the transitional water level can be calculated by the combination of the North Sea level and Rhine flow. It will be further described and developed in this article.

Climate change will influence North Sea level and Rhine flow in the Rhine Delta. In 2006, the Royal Dutch Meteorological Institute (KNMI) worked out two scenarios of sea level rise for the Dutch coast, which resulted in the mean sea level rising from 0.15 up to $0.35 \mathrm{~m}$ by 2050 and from 0.35 up to $0.85 \mathrm{~m}$ by 2100 [8]. For the Rhine River the increasing temperature and changing air circulation patterns are supposed to result in lower summer discharges and higher winter discharges (e.g., [9-12]). The latest research by Caroline A. Katsman, et al. [13] confirmed the above results. They developed a plausible high-end scenario of 0.40 to $1.05 \mathrm{~m}$ mean sea level rise on the coast of the Netherlands by 2100 (excluding land subsidence), using climate models in combination with hydrological models indicated that Rhine peak flow may increase by 5 to $40 \%$ to as much as $22,000 \mathrm{~m}^{3} / \mathrm{s}$ over the $21 \mathrm{st}$ century. Obviously, future mean sea level rise combined with higher winter Rhine flow will increase the probability of extreme water level events in the delta. The adaption to future increasing flood probabilities including the operation of the Maeslant Barrier will be studied in this article.

The goal of this research is to compare the flood frequency with and without the controlled barrier in order to assess the influence of the barrier operations on flood risk reduction. The paper is organized as follows: First a description of the delta area will be presented, followed by the outline of the applied methodology. Next, 'Equal Level Curves' is illustrated, followed by the flood frequency analysis. Next, the parameters of the control operation of the barrier are optimized. Finally, conclusions and future work are presented.

\section{Description of the Rhine Delta}

A schematic graph of the Rhine Delta is shown in Figure 1. In general the discharge of the Rhine River is mainly driven by rains in the South of Germany and snow melt in the Alps. The Rhine flows into the Netherlands at Lobith in the East of the country and out in Hook of Holland in the West. The distance from Lobith to Hook of Holland is approximately 170 kilometers. The sea water flows into 
the delta in Hook of Holland twice per day when the sea level is higher than the water level in the delta. Table 1 and Figure 2 present the measurements used in this research.

The flooding types are divided into three categories in Figure 3: (a) the surge tide coinciding with Rhine flooding; (b) the surge tide coinciding with normal Rhine flow and (c) the normal sea level coinciding with Rhine flooding. The Maeslant Barrier is designed to prevent the surge tide from propagating into the New Waterway (e.g., (a) and (b) in Figure 3). In the case of a barrier closure, the Rhine flow can not discharge into the North Sea, and consequently it accumulates in the delta and results in water level rising. As a result, after the barrier closure, the water level behind the barrier mostly depends on the closure duration, the corresponding Rhine discharge and the storage capacity of the delta, etc. When the water level rises higher than the design safety level, flooding will happen.

Figure 1. The Rhine-Meuse Delta in the Netherlands.

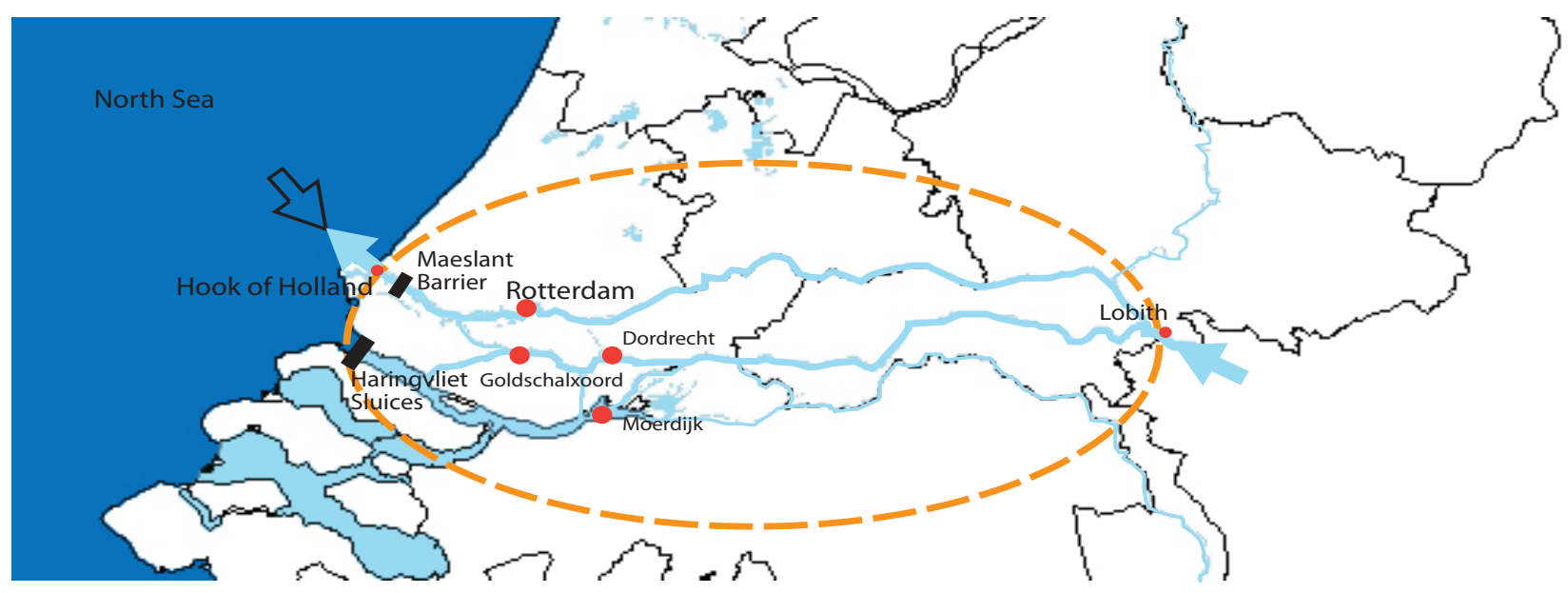

Table 1. Gauge stations.

\begin{tabular}{llc}
\hline \multicolumn{1}{c}{ Gauge station } & \multicolumn{1}{c}{ Unit } & Period (years) \\
\hline Hook of Holland & $\begin{array}{l}\text { High sea water level (m MSL one high } \\
\text { water recording at every tide cycle) }\end{array}$ & $1887-2009$ \\
Lobith & Mean daily discharge $\left(\mathrm{m}^{3} / \mathrm{s}\right)$ & $1901-2009$ \\
Rotterdam & Water level (m MSL one high water & $1940-2009$ \\
& recording at every tide cycle) & \\
\hline
\end{tabular}


Figure 2. (a) One day sea level in Hook of Holland; (b) Annual maximum sea level in Hook of Holland; (c) One year Rhine discharge in Lobith; (d) Annual maximum Rhine discharge in Lobith.

(a)

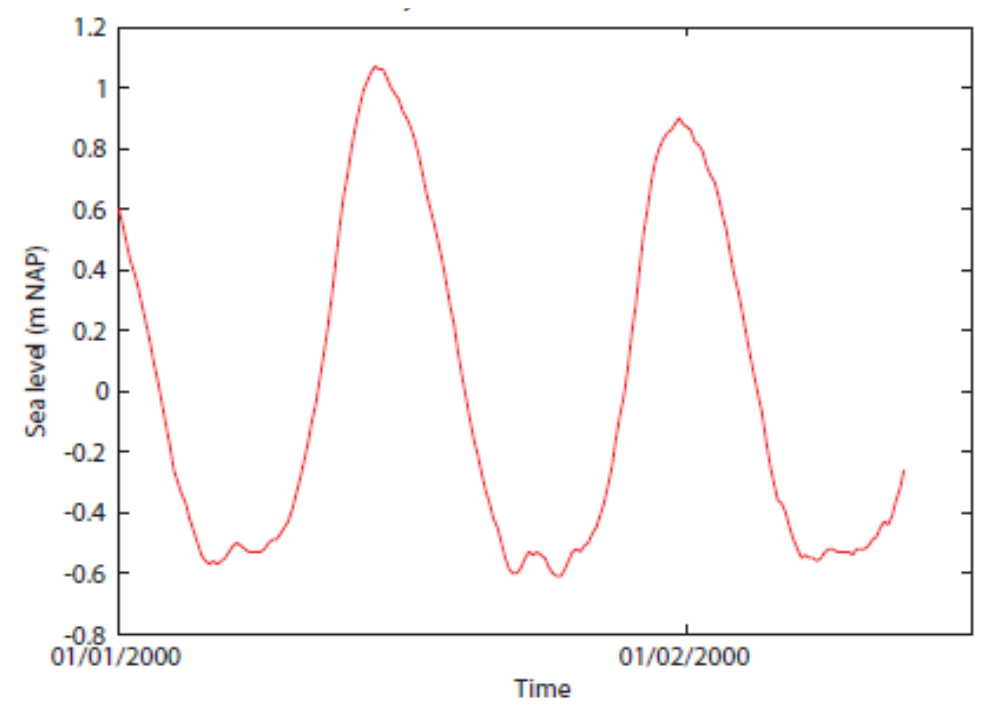

(c)

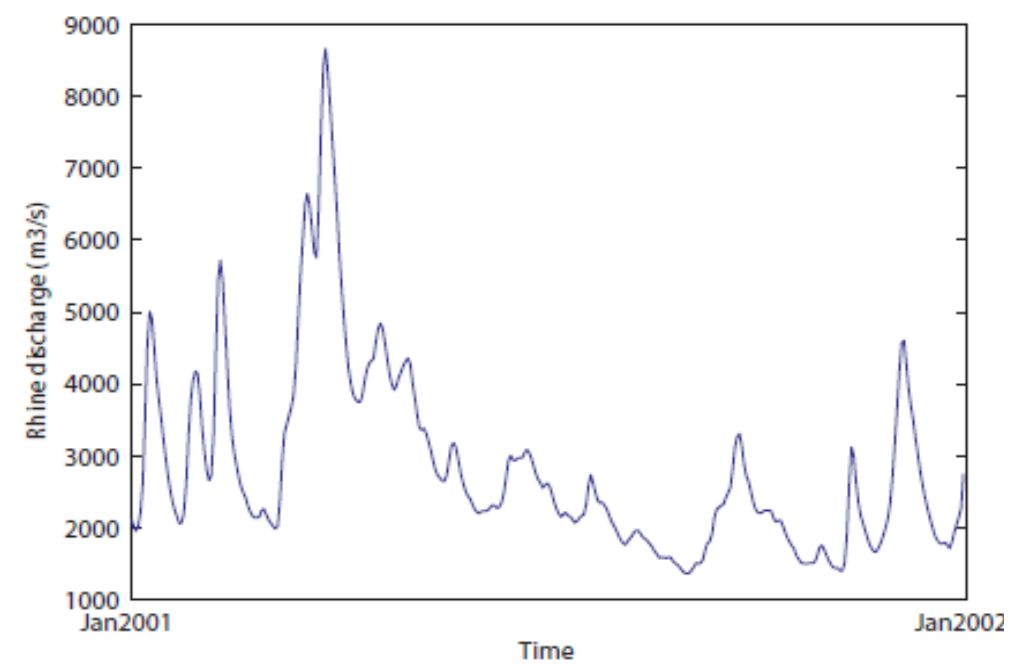

(b)

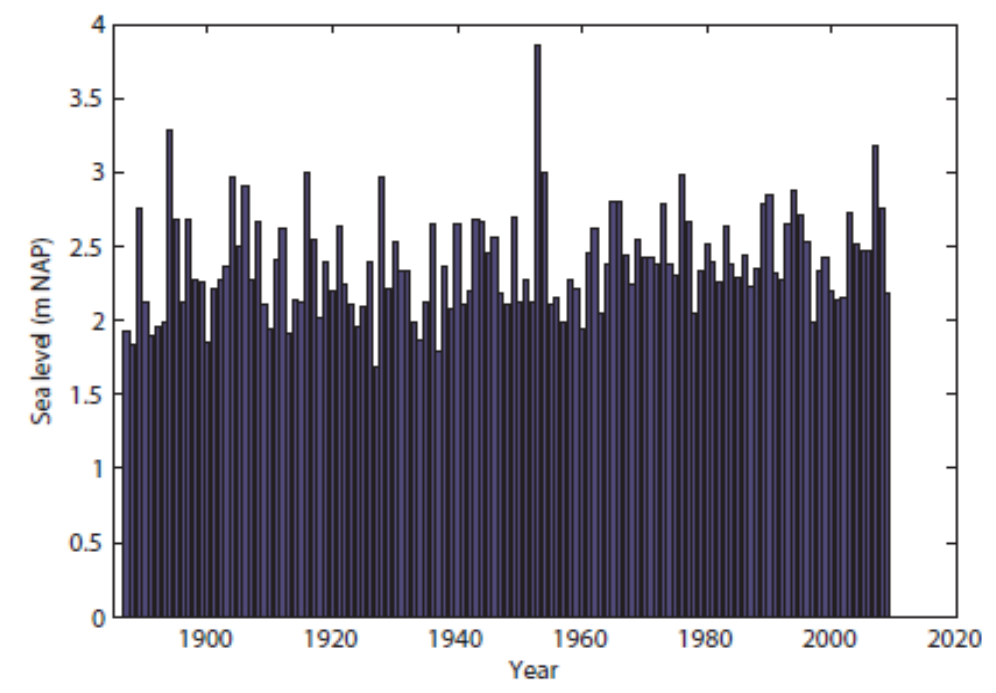

(d)

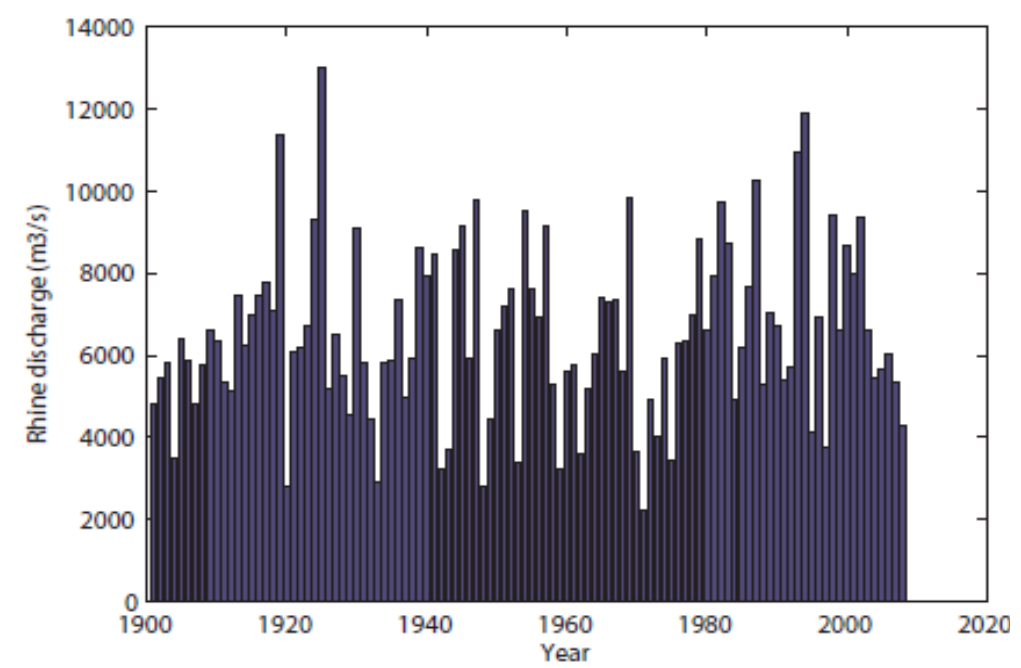


Figure 3. Flooding types and the function of the Maeslant Barrier: (a) The surge tide coinciding with Rhine flooding; (b) the surge tide coinciding with normal Rhine discharge; (c) the normal sea level coinciding with Rhine flooding.
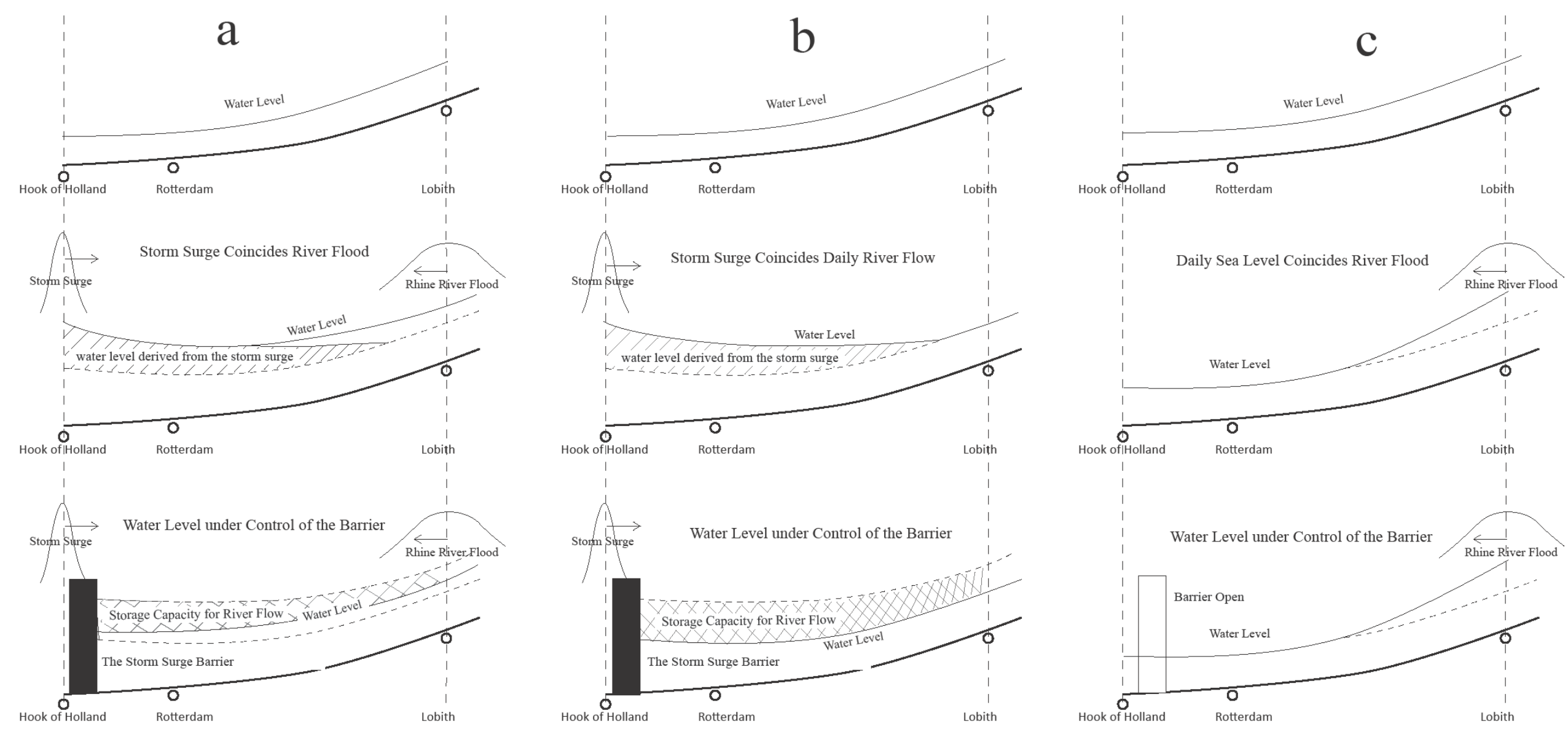


\section{Methodology}

In order to obtain statistically significant results for the flood frequency analysis in Rotterdam, the following steps are undertaken (Figure 4):

(1) To investigate the historical observations in order to detect and remove trends and discontinuities.

(2) To derive the probability density functions for annual maximum sea levels and their corresponding Rhine flows.

(3) To examine the degree of correlation between the above sea levels and Rhine flows.

(4) To develop an exceedance probability function of the Rotterdam water level using the above probability functions and 'Equal Level Curves'.

(5) To work out the exceedance joint probability function using Monte Carlo Simulations.

(6) To repeat steps 2 to 6 to build up future sea level rising scenarios.

Figure 4. Flow chart of methodology.

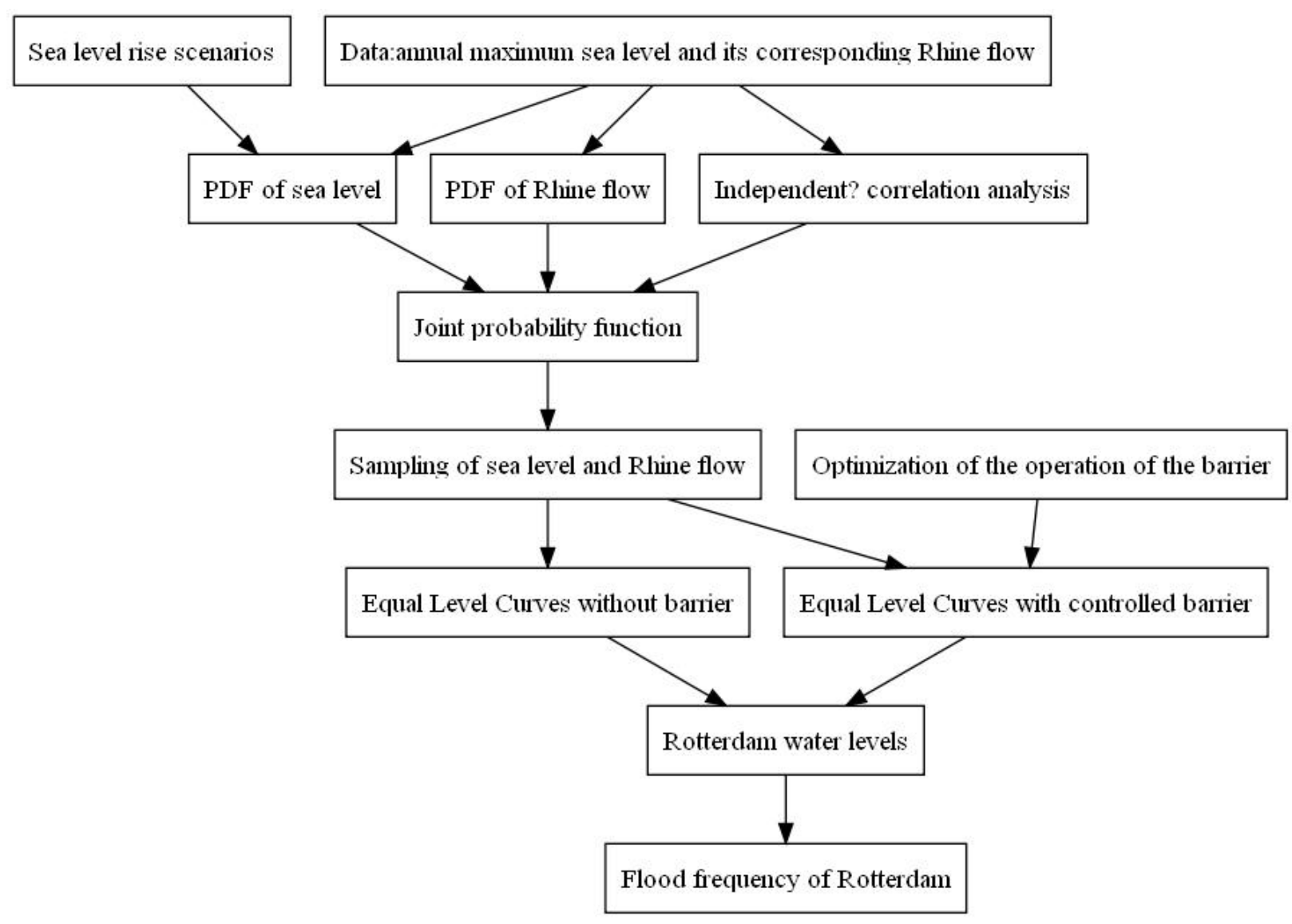

\section{Simulation of the Water Level at Rotterdam}

A detailed hydrodynamic model of the delta, calibrated every five years, has been developed [14]. However, this model is unfit for the current research because of the long calculation time. Note that a large amount of simulations needs to be executed in order to reach statistically significant results. So an Equal Level Curves approach is used [7]. It requires less information and offers a very fast calculation. Moreover, it is accurate enough for the purpose of this research, and convenient to 
combine with the operation of the Maeslant Barrier. The model then can become the basis for analyzing the influence of the operation of the barrier on the flood frequency at Rotterdam. In the water level calculations, we assume that the dike level is infinitely high and no dike breaches happen.

\subsection{Equal Level Curves}

Equal Level Curves approach is a simple steady state function, which can simulate the highest water level at Rotterdam by up-down boundary conditions during one tidal period.

$$
h_{\text {basin }}=h_{\text {sea }}+\left(\frac{Q_{\text {river }}}{\mu A_{\text {mouth }}}\right)^{2} \cdot \frac{1}{2 \cdot g}
$$

where $h_{\text {basin }}$ stands for the highest water level at a specific location in the delta (Rotterdam in this case); $h_{\text {sea }}$ stands for the highest water level at Hook of Holland; $Q_{\text {river }}$ is the Rhine flow at Lobith; $\mu$ is the discharge coefficient; $A_{\text {mouth }}$ stands for the surface area of the cross section in Hook of Holland and $g$ is the gravitational acceleration. $Q_{\text {river }}$ is assumed to be a constant value because the Rhine flood wave usually lasts about ten days, which is much longer than the high sea level period.

The parameters in Equation (1) are estimated using historical data. For practical reasons, only the product of $\mu$ and $A_{\text {mouth }}$ is of importance. In the case of Rotterdam, the peak events are selected from annual maximum sea levels and the annual maximum Rhine flow from 1940 to 2009 , amounting to 137 events in total. ' $\mu A_{\text {mouth }}$ ' is estimated using linear regression and its value is $3,620 \mathrm{~m}^{2}$.

In Figure 5 all points lie near the linear line, except point A. Point A stands for the first barrier closure event on 9 November 2007 due to the severe storm "Tilo". The observation value is about $1.5 \mathrm{~m}$ MSL under the current operation of the Maeslant Barrier, as the barrier helps to stop the surge tide from propagating into the delta. In this case, point $A$ is ignored. On the other hand, the November 9 closure event gives a valuable measurement that can be used to model the delta's behavior during closure.

Figure 5. Comparison of the observed and simulated water levels at Rotterdam.

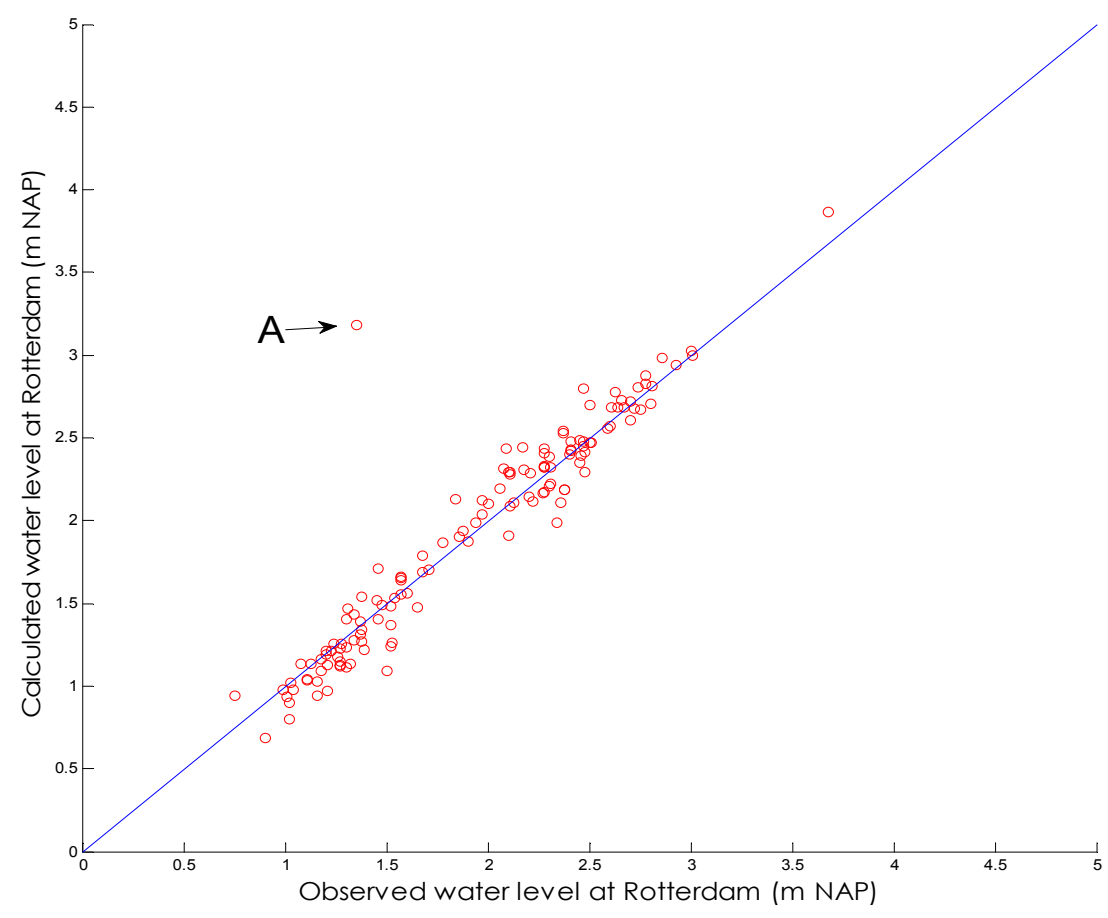


With the available parameter $\mu A_{\text {mouth }}$ 'Equal Level Curves' can be drawn (see Figure 6). Besides, as can be seen in Figure 7, Rotterdam water level is mostly influenced by the sea water level and to a lesser extent by Rhine discharge.

Figure 6. Equal Level Curves for Rotterdam.

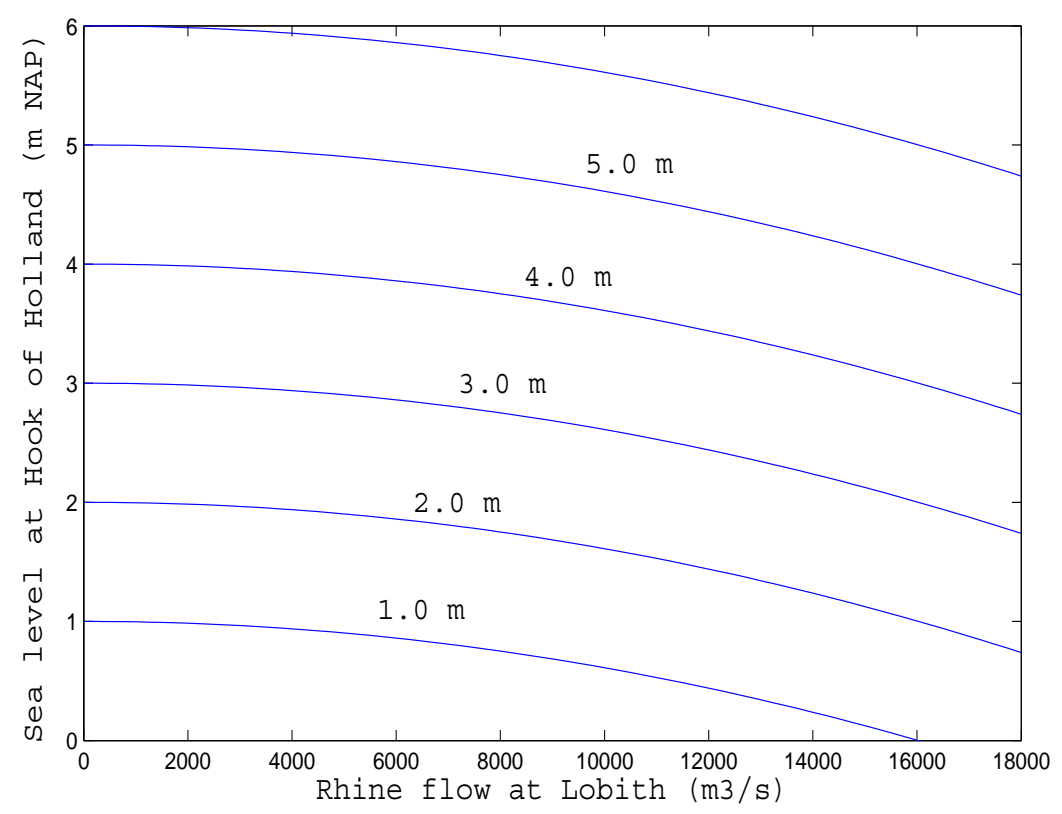

Figure 7. Observation of water level at Rotterdam and Hook of Holland.

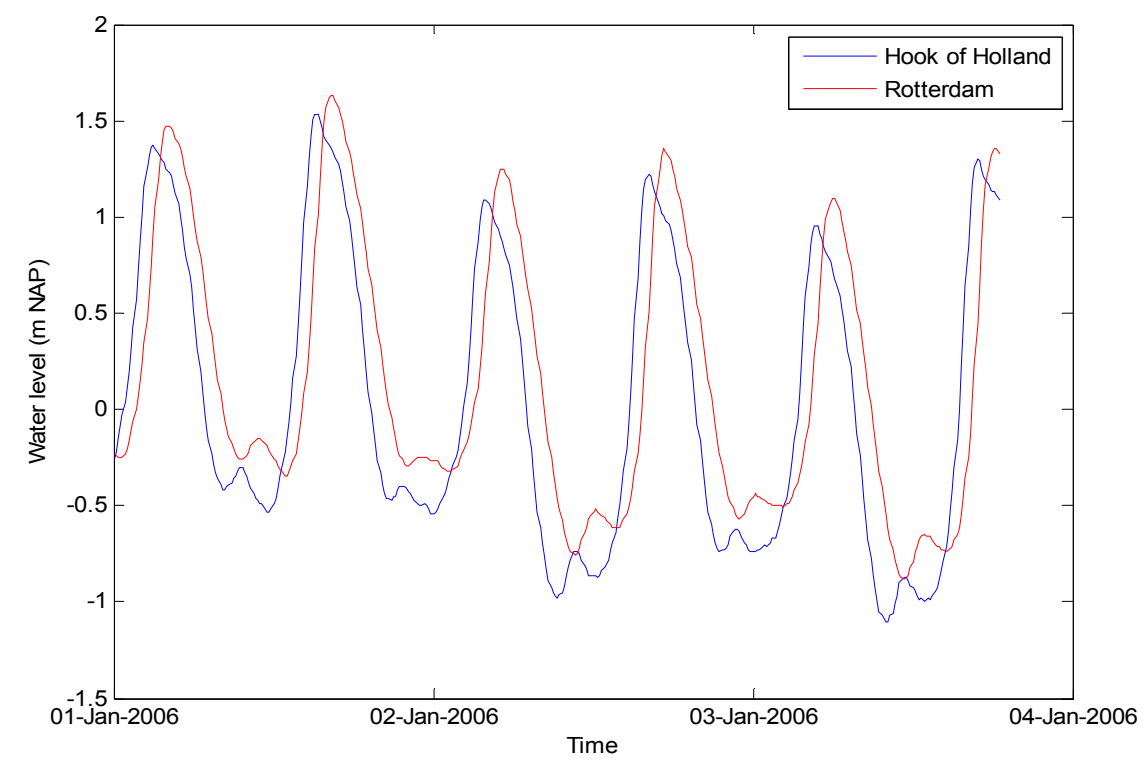

\subsection{Reservoir Model after Closure of the Maeslant Barrier}

To consider the effect of the Maeslant Barrier closure, the operation control is combined with Equal Level Curves. During the storm surge, the high sea level is kept out of the basin by closing the Maeslant Barrier. Afterwards the water level behind the barrier will rise because the Rhine flow is stored here. The water level in the basin after the barrier closure becomes: 


$$
h_{b a \sin }=h_{b a \sin , c}+\frac{Q_{r i v e r} \cdot \Delta T}{B_{B a \sin }}
$$

where $h_{\text {basin }}$ is the water level in the delta after the closure duration $\Delta T ; h_{b a s i n, c}$ stands for the water level in the delta directly after the closure; $Q_{\text {river }}$ is the Rhine flow at Lobith; $B_{\text {basin }}$ stands for the surface area of the reservoir where water can be stored.

$h_{\text {basin, }}$ stands for the average water level behind the barrier. As the water level is not constant along the river, the water levels at four locations (Rotterdam (R), Goidschalxoord (G), Dordrecht (D), and Moerdijk (M)) are chosen at the moment of closing the barrier and their average level is taken as $h_{\text {basin,c. }}$. The water levels at these four locations at time $t$ depend on the sea level delayed by several hours and the Rhine discharge delayed by 24 hours (Equations (3)-(6)), because the propagations of the flood waves and surge tides take time.

$$
\begin{gathered}
h_{R}(t)=0.9735 \cdot h_{\text {sea }}(t-3600)+7.781 \cdot 10^{-9} \cdot Q_{\text {river }}^{2}(t-86400) \\
h_{G}(t)=0.7335 \cdot h_{\text {sea }}(t-4200)+1.013 \cdot 10^{-8} \cdot Q_{\text {river }}^{2}(t-86400) \\
h_{D}(t)=0.6065 \cdot h_{\text {sea }}(t-7200)+1.737 \cdot 10^{-8} \cdot Q_{\text {river }}^{2}(t-86400) \\
h_{M}(t)=0.3753 \cdot h_{\text {sea }}(t-11400)+1.458 \cdot 10^{-8} \cdot Q_{\text {river }}^{2}(t-86400)
\end{gathered}
$$

The parameters of these four equations are estimated by system identification on historical measurements according to Equation (1). The time unit of $t$ is seconds.

The parameter $B_{\text {basin }}$ can be estimated by inverting Equation (2) into:

$$
B_{b a \sin }=\frac{Q_{\text {river }} \cdot \Delta T}{h_{b a \sin }-h_{b a \sin , c}}=\frac{\left(\frac{8}{9} Q_{\text {rhine }}+Q_{\text {Meuse }}\right) \cdot \Delta T}{\Delta h}
$$

The flow of the small branch of the Rhine towards the North and the Meuse flow are considered in order to get more accurate values of $B_{\text {basin }}$. The factor 8/9 comes from the distribution of the Rhine River inflow of which $1 / 9$ flows towards the North to the Lake IJssel. $\Delta T$ stands for the water level rise period in the delta during the closure time. During the closure event of 2007, the daily mean discharge of the Rhine was $1,171 \mathrm{~m}^{3} / \mathrm{s}$, the daily mean discharge of the Meuse was $148 \mathrm{~m}^{3} / \mathrm{s}$ and the water level at Rotterdam rose from 0.70 to $1.12 \mathrm{~m}$ during the 15 hour closure. In Figure 8, the water level derivative is more or less constant during the closure of the barrier. The value of $B_{b a s i n}$ is estimated to be $152,000,000 \mathrm{~m}^{2}$.

Given a certain storm surge event, the closure duration of the barrier $\Delta T$ depends on the operation of the barrier. There are three main switch levels related to $\Delta T$ in the operation: the closing decision level $H_{s}$, the closing level $H_{c}$ and the critical Rhine flow $Q_{s}$. The first one, $H_{s}$, is checked on the predicted highest level at Rotterdam for the next 24 hours, while the second, $H_{c}$, is the sea level at which, after the switch $H_{s}$ has been activated, the barrier is actually closed. The third, switch $Q_{s}$, is the critical value of Rhine flow above which the barrier's operation will change in case there is not enough storage for high Rhine flow. After closure of the barrier, as the delta water level rises higher than the sea level, the barrier opens, allowing water to be discharged out of the area. The present settings for $H_{s}, H_{c}$ and $Q_{s}$ are $3.00 \mathrm{~m} \mathrm{MSL}, 2.00 \mathrm{~m} \mathrm{MSL}$ and $6,000 \mathrm{~m}^{3} / \mathrm{s}$, respectively [15]. These operation parameters are such 
that the levees in Rotterdam correspond to the flood safety standards and the barrier closes as seldom as possible. This closure frequency needs to be as low as possible, because it delays navigation to and from the Rotterdam harbor. The control operation rules are shown below in Figure 9.

Figure 8. Rotterdam water level during the closure event of November 9, 2007.

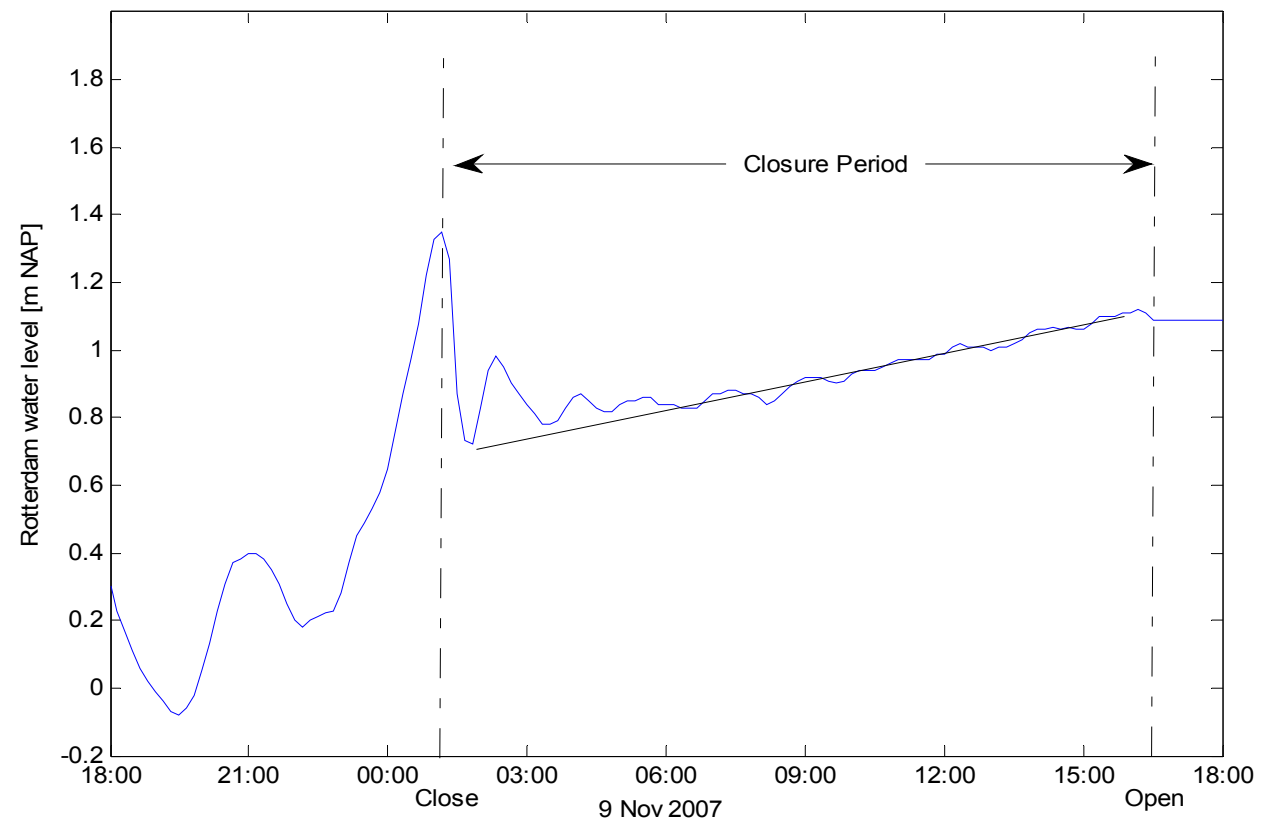

Figure 9. The operation control of the Maeslant Barrier.

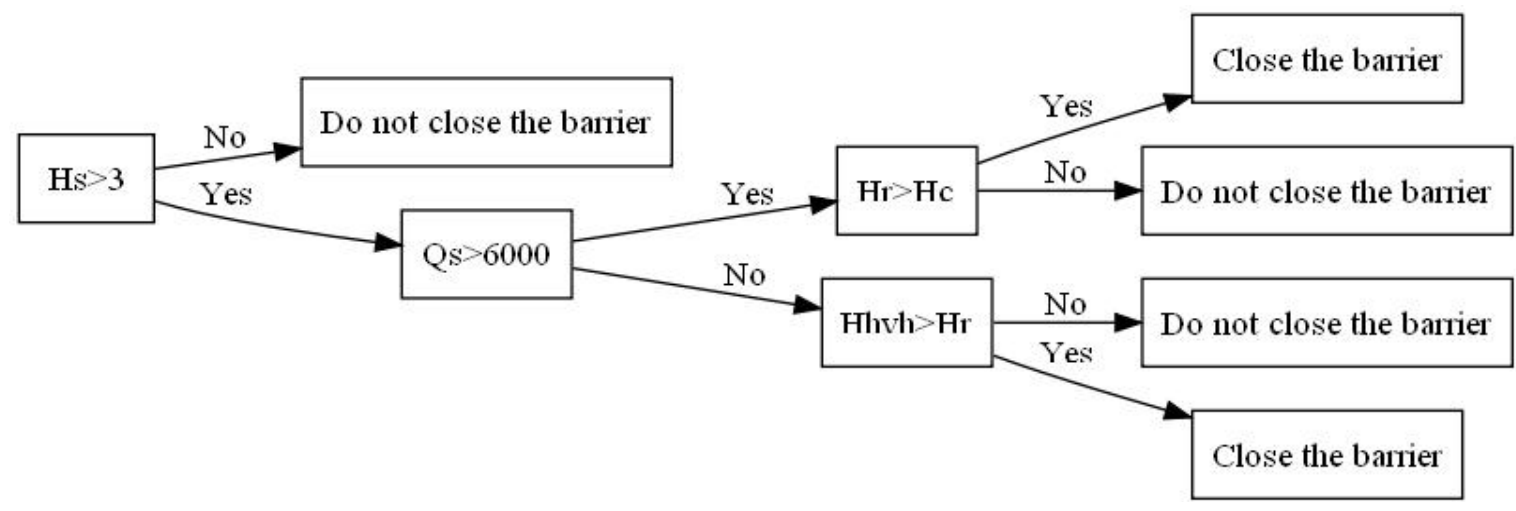

In order to execute Equation (2) in the simulations, the following assumptions are applied to the sea level boundary:

First, the design hydrograph of high sea level in Hook of Holland is considered. The sea level consists of the astronomical tide, the wind set up and the mean sea level. The mean sea level is $0 \mathrm{~m}$ MSL. The assumption is that the astronomical tide and the wind set up are independent but their peak values coincide.

$$
h_{\text {sea }}(t)=h_{\text {wind set up }}(t)+h_{\text {astronomical tide }}(t)+h_{0}
$$

Wind set up is a dynamic process and its variation with time could be roughly approximated by Equation 9 [16]. 


$$
h_{\text {wind set up }}(t)=h_{w \max } \cos ^{2}\left(\frac{\pi}{D}\left(t-\frac{D}{2}\right)\right)
$$

$h_{w \max }$ is the maximum wind set up during a storm. The value of $h_{w \max }$ equals the given sea level minus the astronomical tide amplitude. $D$ stands for the duration of the wind set up which is set at a constant value of 50 hours [16].

The astronomical tide is assumed to be a sinusoidal wave. Its amplitude and duration are selected by a yearly mean value: The peak to peak amplitude $h_{a}$ is $1.67 \mathrm{~m}$ and the duration of one tidal cycle $T$ is 12.4 hours.

$$
h_{\text {astronomical tide }}(t)=\frac{h_{a}}{2} \cdot \sin \left(\frac{2 \pi}{T} \cdot\left(t-\frac{D}{2}+\frac{\pi}{2}\right)\right)
$$

Second, in the simulation, $h_{\text {basin }}$ is determined by Equation (1). In the event of closure, $h_{\text {basin }}$ can be determined according to Equations (2)-(10) and Figure 9.

\section{Flood Frequency Analysis}

In the flood frequency analysis, the annual maximum sea levels and the corresponding Rhine flows are chosen, since the Rotterdam water level is mostly influenced by the sea water level. First, these data are tested; second, their probability density functions (PDF) are estimated; third, their relationship is estimated. Finally the exceedance joint probability function of the Rotterdam water level is derived.

\subsection{Historical Data Analysis}

The behavior and course of a river or sea condition may change considerably over long time periods due to artificial or natural causes, and therefore several tests must be executed to check whether all observations from hydrologic events come from the same population. The Mann Kendall test is commonly applied to assess the significance of trends in hydro-meteorological time series such as stream flow, temperature and precipitation (e.g., [17,18]). The Spearman's rho (SR) test is another rank-based non-parametric statistical test that can also be used to detect monotonic trends in a time series (e.g., [19,20]). The Wilcoxon's Rank Sum test is used to test if abrupt points exist in time series [21]. The annual maximum sea level series and its corresponding Rhine flow (1901-2009) are examined using the above tests.

In Table 2 the results of trend tests show that there is a positive trend in the annual maximum sea level series at Hook of Holland. In the First Delta Plan a $0.2 \mathrm{~m}$ sea level rise during the 20th century was accepted and included and was widely used (e.g., [22]). In this research, the annual maximum sea level data is corrected by a sea level rise of $0.002 \mathrm{~m}$ per year; the results then satisfy the null hypothesizes in Table 3. On the contrary, the Rhine flow data accepts the null hypothesizes in Table 4. Although the Rhine upstream area has undergone a great deal of changes over the past 100 years, these changes are of minimal importance in extreme Rhine discharge. Therefore we assume that these data are homogenous. 
Table 2. Tests on the annual maximum sea level at Hook of Holland.

\begin{tabular}{cccc}
\hline $\begin{array}{c}\text { Annual maximum sea level in } \\
\text { Hook of Holland }\end{array}$ & \multicolumn{2}{c}{ Trend test } & Jump test \\
\hline Test (at the significance & Mann Kendall test & Spearman's rank correlation & Jump test \\
level 0.05) & & coefficient method & \\
Null hypothesis $\left(\mathrm{H}_{0}\right)$ & No trend & No trend & No abrupt points \\
P-value & 0.0058 & 0.0054 & 0.1318 \\
Reject $\mathrm{H}_{0}$ & Yes & Yes & No \\
\hline
\end{tabular}

Table 3. Tests on the corrected annual maximum sea level at Hook of Holland.

\begin{tabular}{cccc}
\hline $\begin{array}{c}\text { Annual maximum sea level in } \\
\text { Hook of Holland }\end{array}$ & \multicolumn{2}{c}{ Trend test } & Jump test \\
\hline Test & Mann Kendall test & Spearman's rank correlation & Jump test \\
& No trend & No trend & No abrupt points \\
Null hypothesis $\left(\mathrm{H}_{0}\right)$ & 0.71 & 0.69 & 0.21 \\
P-value & No & No & No \\
Reject $\mathrm{H}_{0}$ & & & \\
\hline
\end{tabular}

Table 4. Tests on Rhine flow at Lobith.

\begin{tabular}{cccc}
\hline Rhine flow in Lobith & \multicolumn{2}{c}{ Trend test } & Jump test \\
\hline Test & Mann Kendall test & Spearman's rank correlation & Jump test \\
& & coefficient method & \\
Null hypothesis $\left(\mathrm{H}_{0}\right)$ & No trend & No trend & No abrupt points \\
P-value & 0.98 & 0.96 & 0.16 \\
Reject $\mathrm{H}_{0}$ & No & No & No \\
\hline
\end{tabular}

\subsection{Probability Density Functions of Annual Maximum Sea Levels and the Corresponding Daily}

Rhine Discharge

The PDF of the annual maximum sea level is calculated. According to the extreme value theory, the annual maximum sea level belongs to one General Extreme Value distribution [22] (GEV). The Maximum Likelihood Method is used to estimate the parameters of the GEV distribution. Then the PDF becomes:

$$
\left.f(x)=\frac{1}{\sigma_{H W}}\left(1+\xi_{H W} \frac{x-\mu_{H W}}{\sigma_{H W}}\right)^{\left(-\frac{1}{\xi_{H W}}\right)-1} e^{-\left(1+\xi_{H W}\right.} \frac{x-\mu_{H W}}{\sigma_{H W}}\right)^{-\frac{1}{\xi_{H W}}}
$$

where the value of $\xi_{H W}$ is -0.02 ; the value of $\sigma_{H W}$ is $0.26 \mathrm{~m} \mathrm{MSL}$; the value of $u_{H W}$ is $2.35 \mathrm{~m} \mathrm{MSL}$; $x$ stands for the sea level at Hook of Holland and its unit is m MSL.

The daily mean Rhine flow that corresponds to the annual maximum sea level fits the lognormal distribution according to the Kolmogorov-Smirnov test and the Anderson-Darling test. The other reason to choose the lognormal distribution is that it is still possible to generate some extreme peak values for Rhine discharge, and subsequently the combination of a surge tide and Rhine peak flow is possible to include. The Maximum Likelihood Method is used to estimate the parameters of the lognormal distribution. Then the PDF becomes: 


$$
f(x)=\frac{1}{x \sigma_{Q} \sqrt{2 \pi}} e^{-\frac{\left(\ln x-u_{Q}\right)^{2}}{2 \sigma_{Q}{ }^{2}}}
$$

where the value of $u_{Q}$ is $7.69 \mathrm{~m}^{3} / \mathrm{s}$; the value of $\sigma_{Q}$ is $0.50 \mathrm{~m}^{3} / \mathrm{s} ; x$ stands for the daily mean Rhine discharge and its unit is $\mathrm{m}^{3} / \mathrm{s}$.

Figure 10 indicates the return period of sea levels based on the Equation (11) at Hook of Holland.

Figure 10. Return period of the sea levels at Hook of Holland.

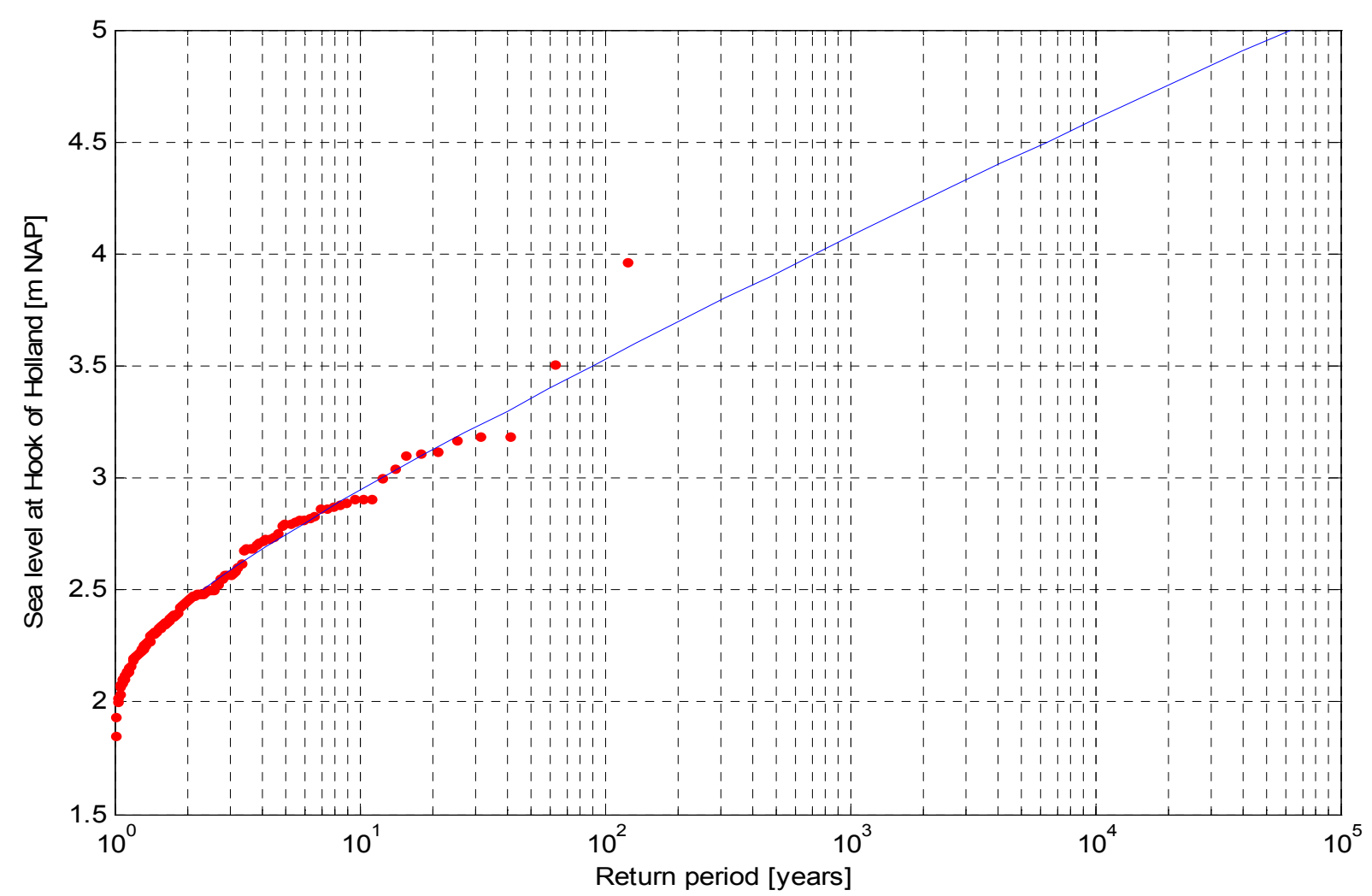

\subsection{Relationship between High Sea Level and Rhine Discharge}

The annual maximum sea levels and their corresponding daily Rhine flows are plotted in Figure 11. Their relationship is calculated by Pearson's coefficient $r$. The value of $r$ is -0.05 , thus it shows independence between these two variables. These results are also supported by other references (e.g., $[5,6])$.

\subsection{The Exceedance Joint Probability Function of Rotterdam Water Level}

In order to get the exceedance joint probability function of the Rotterdam water level, PDFs of annual maximum sea levels and the corresponding daily Rhine flow (Equations (11) and (12)) are chosen. These two variables are independent. The relationship is given by Equation 13:

$$
P\left(h_{\text {basin }}\right)=\iint_{\Omega} h_{\text {basin }}\left(h_{\text {sea }}, Q_{\text {river }}\right) p\left(h_{\text {sea }}\right) \cdot p\left(Q_{\text {river }}\right) d h_{\text {sea }} d Q_{\text {river }}
$$


In which: $\Omega$ is the complement area of $(1-\Omega)$, which is the shadow area in Figure 12 enclosed by the contour line of a particular value of $h_{\text {basin }}$, defined over the $h_{\text {sea }}$ and $Q_{\text {river }}$ axis; $h_{\text {basin }}\left(h_{\text {sea }}, Q_{\text {river }}\right)$ relates to Equations (1) and (2), and $P\left(h_{\text {sea }}\right)$ and $P\left(Q_{\text {river }}\right)$ stand for Equations (11) and (12), respectively.

An analytical method for calculating Equation (13) is infeasible. Instead, Monte Carlo Simulations offer a more flexible way to estimate the exceedance probability (e.g., [23]).

Figure 11. Annual maximum sea levels against corresponding Rhine flows.

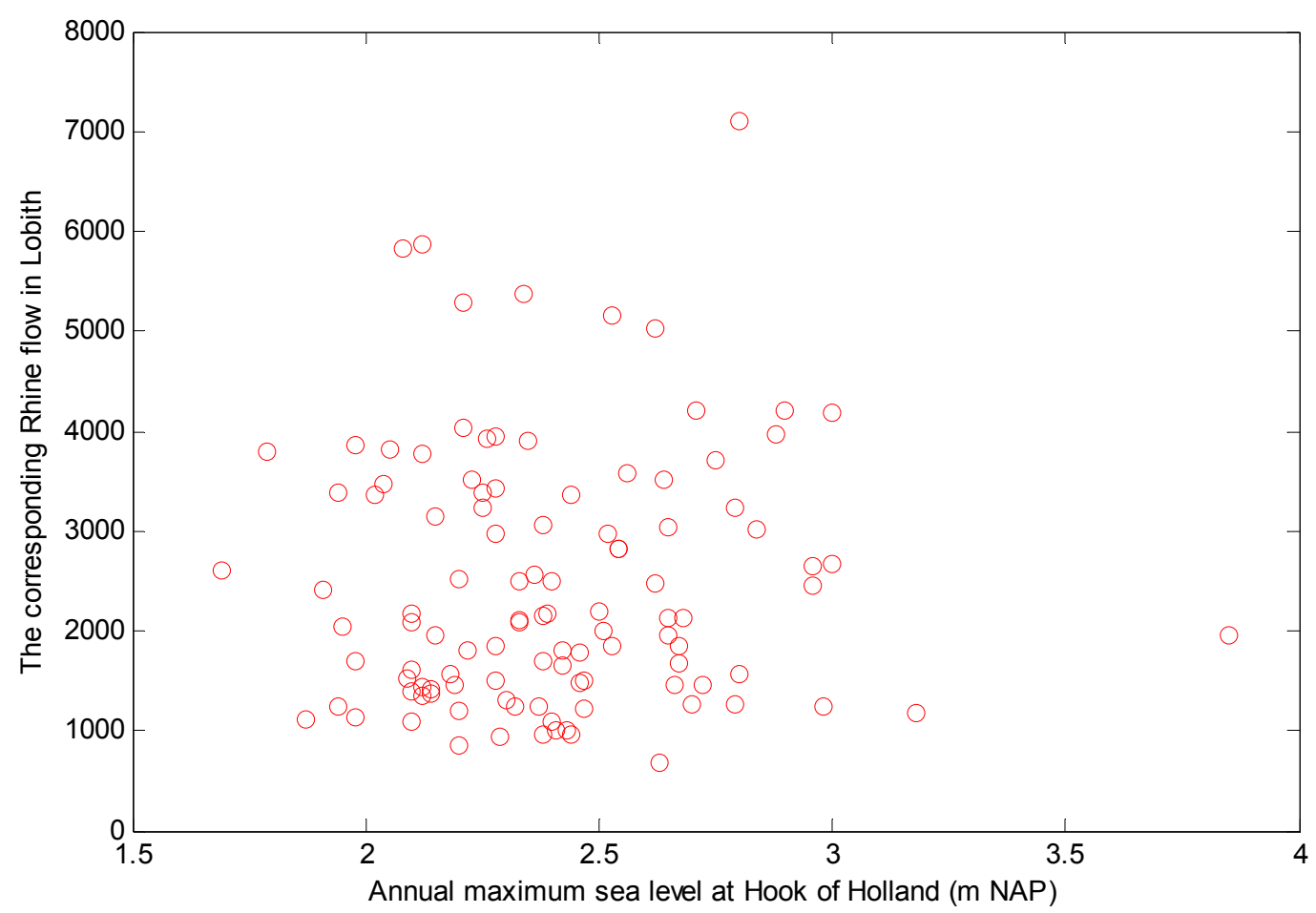

Figure 12. Integration for the exceedance probability of a particular $\mathrm{H}_{\text {basin }}$.

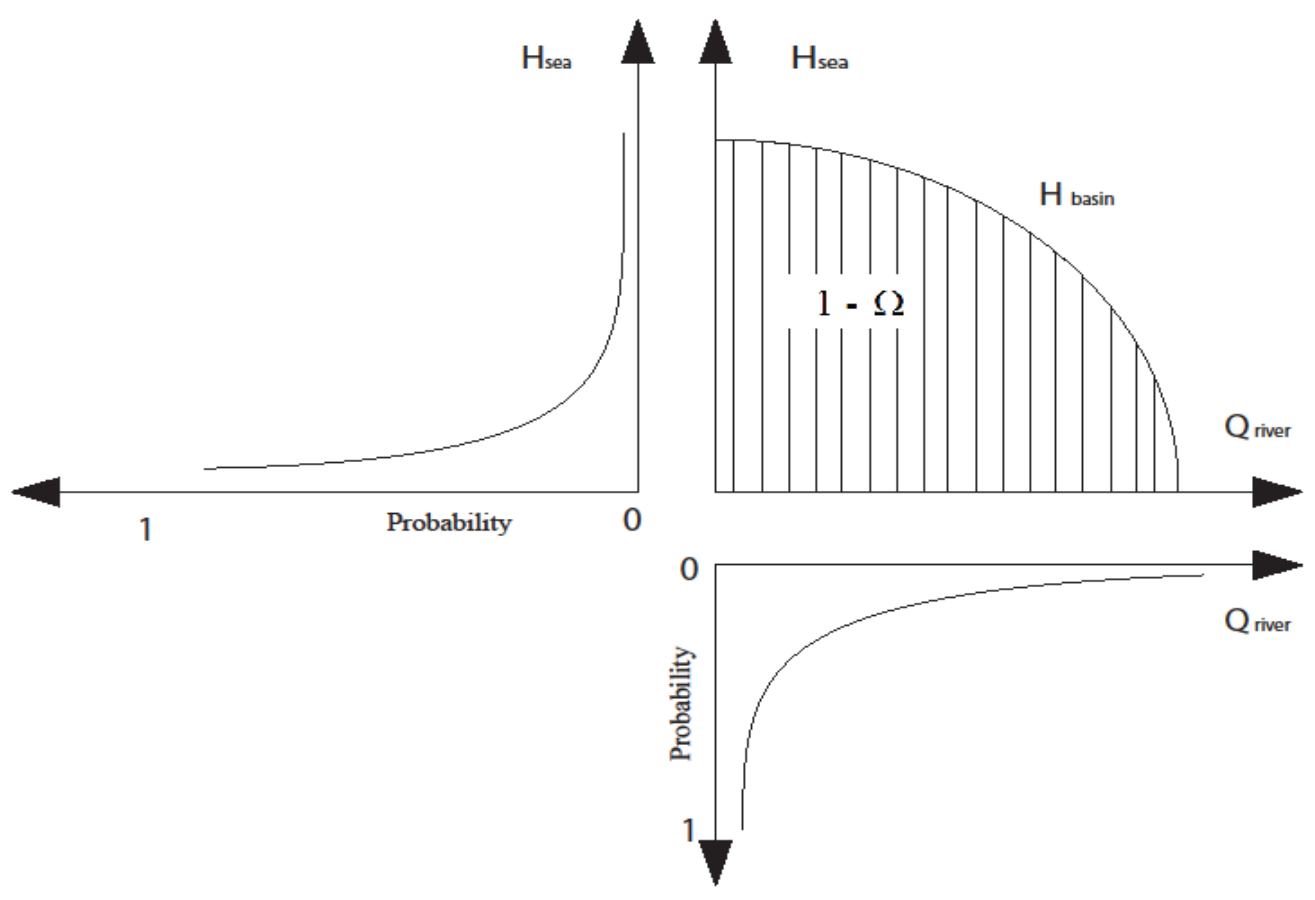




\subsection{Sea Level Rise}

Future climate change is taken into consideration, but in this research attention is only paid to sea level rise. There are two sets of scenarios given by Royal Netherlands Meteorological Institute (KNMI) [8]. In this research the worst set is used regarding sea level rise in Hook of Holland (Table 5). Although the Maeslant Barrier was designed to stand the mean sea level rise by 2050 and it will probably fail by 2100 due to the mean sea level rise, in this research it is assumed to function well until 2100 .

Table 5. The scenarios of mean sea level rise.

\begin{tabular}{cc}
\hline Year & Mean Sea Level Rise (m) \\
\hline 2050 & 0.35 \\
2100 & 0.85 \\
\hline
\end{tabular}

\section{Results}

\subsection{Return Period Results}

Large enough combination samples of sea level and Rhine discharge are generated by Monte Carlo Simulation according to Equations (11) and (12). The 'Equal Level Curves' described in Section 4 runs these simulated combinations and results in the corresponding water levels at Rotterdam. The exceedance probability of the water levels results in a water level-return period curve as can be seen in Figure 13. Note that the failure probability of the Maeslant Barrier is not taken into consideration. Considering the effect of the Maeslant Barrier on the flood frequency, the curves are separated into two parts: one without the barrier, and the other with the controlled barrier. The scenarios considering future sea level rise are found by adjusting the PDF values by adding the rise in mean sea level to all points of the sea level PDF, assuming that the basin storage behavior and the operation remain the same. The Maeslant Barrier is designed to be able to withstand sea level rise until 2050.This article assumes that the Maeslant barrier is able to withstand sea level rise until 2100. The results can be seen below in Figure 13.

The operation of the Maeslant Barrier effectively reduces the flood frequency. In the scenario of 2010, due to the barrier, the return period of $3.0 \mathrm{~m}$ MSL is increased from 10.9 years to about 2,400 years. The return period of other high water levels is also increased. For example, the return period of $4.0 \mathrm{~m} \mathrm{MSL}$ water level (the design safety level) is increased from 609 years to 46,950 years.

However, future sea level rise will increase the flood frequency significantly, and therefore the return periods of all the water levels will drop largely. For example, the return period of $3.0 \mathrm{~m} \mathrm{MSL}$ will reduce from 10.9 years to 3.23 years in 2050 and to 1.10 years in 2100 . The return period of a 4.0 m MSL water level (the design safety level) will reduce from 609 years to 141 years in 2050 and to 19 years in 2100 .

The operation of the barrier can partly compensate the effect of the future sea level rise. According to the current operation, the barrier will increase the return period of $4.0 \mathrm{~m} \mathrm{MSL}$ water level from 141 years to 16,420 years in 2050 and from 19 years to 3849 years in 2100 . In conclusion the barrier reduces the flood frequency effectively for the present situation and for future sea level rise scenarios. 
Figure 13. Return period at different scenarios.

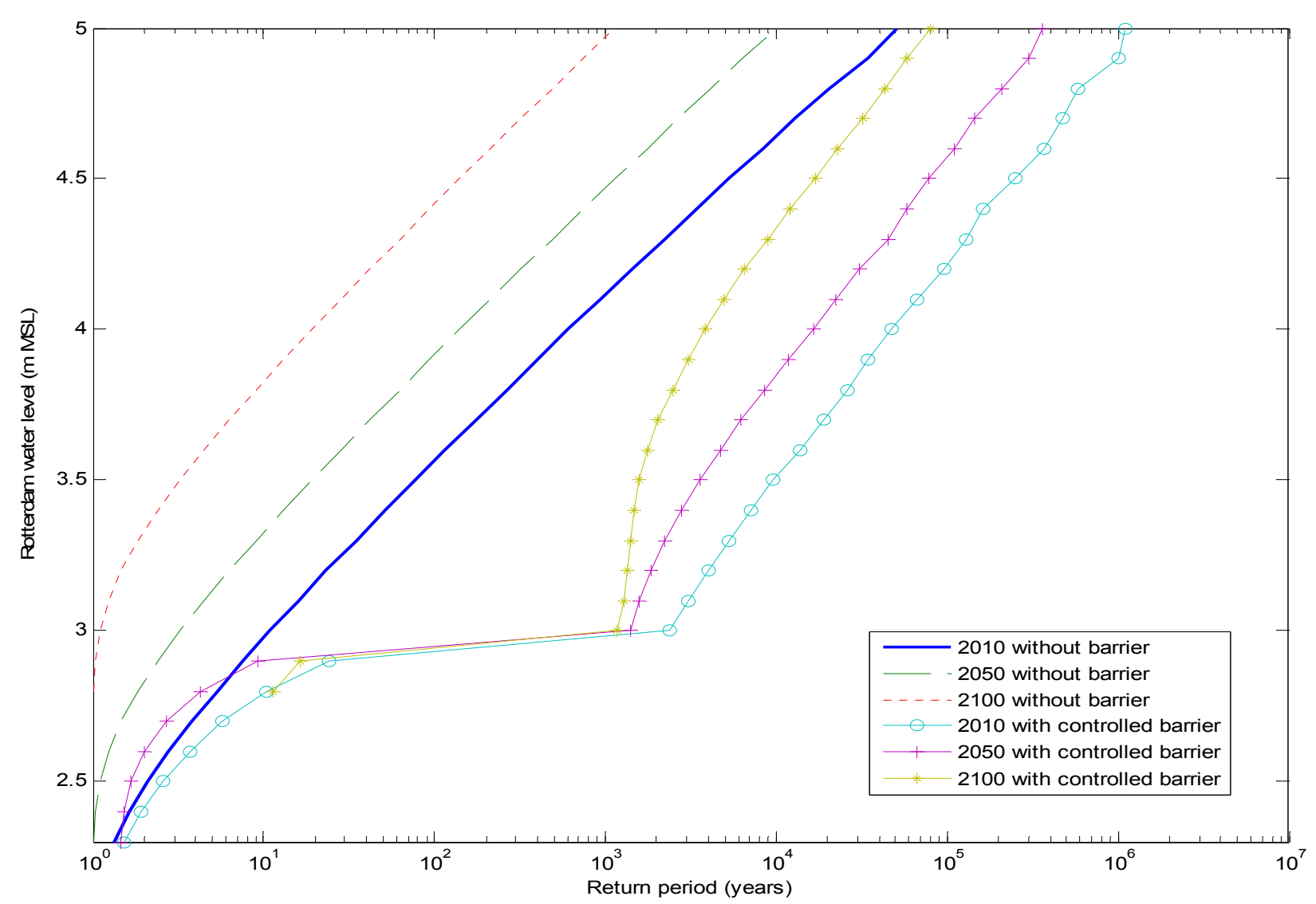

\subsection{Sensitivity Test}

When a storm surge is approaching, it is of vital importance to decide whether and when to close the Maeslant Barrier in advance. The operation of the closure process depends on three parameters: first, the closing level $H_{c}(2.0 \mathrm{~m} \mathrm{MSL})$; second, the closing decision water level at Rotterdam $H_{s}$ (3.0 m MSL); third, the critical Rhine flow $Q_{s}\left(6000 \mathrm{~m}^{3} / \mathrm{s}\right)$. The sensitivity tests for the three parameters show how much the water levels are influenced.

In Figure 14, it can be seen that a changing $H_{s}$ does not influence the return periods of water levels higher than $H_{s}$. This is due to the fact that $H_{s}$ is the parameter on which to base the closing decision. For higher return period events the level for which this parameter stands is exceeded due to high river flows storing in the delta. However, the increase of $H_{s}$ is beneficial for navigation as it lowers the frequency of the closure events. But in this article flood safety is a primary concern, and therefore $H_{s}$ should be determined in a conservative way.

The sensitivities to the flood frequency for $H_{c}$ and $Q_{s}$ are quite small. The reason is that in the simulation these high water level events resulting from high Rhine flow could not be reduced by the closure process of the barrier. 
Figure 14. Return periods for different values of $H_{s}$ in 2010.

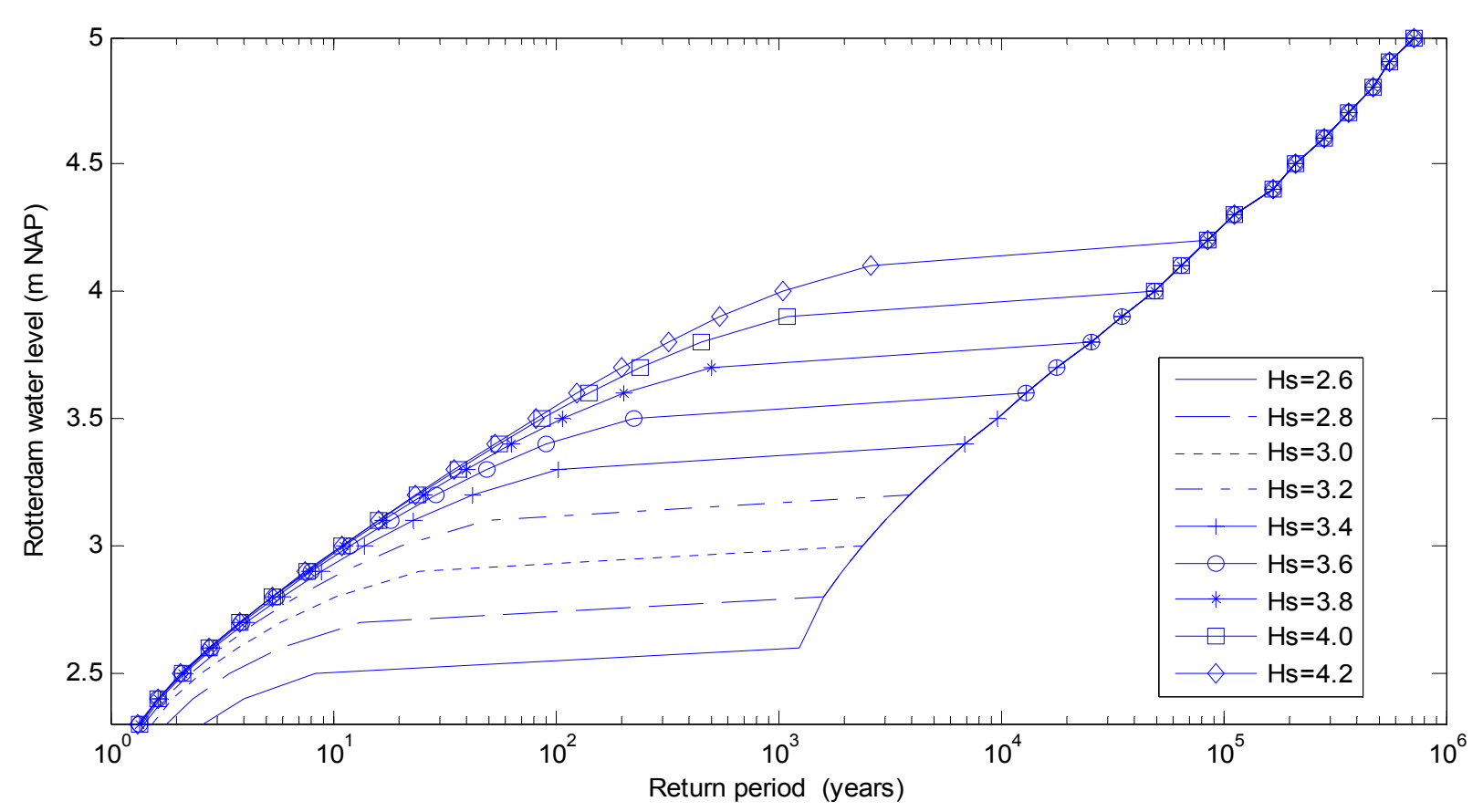

\section{Conclusions and Recommendations}

This article demonstrates how the operation of a storm surge barrier can strongly influence the flood frequency in a delta area. According to the model in this paper, under the current Maeslant barrier operation system, a water level of $4.0 \mathrm{~m}$ in Rotterdam will be reached with a return period of 46,948 years in 2010, 16,420 years in 2050, 3,849 years in 2100. In the future, the port of Rotterdam will be closed once every 3.2 years in 2050 and once every 1.1 years in 2100 under the current control operation $\left(H_{s}, 3.0 \mathrm{~m} \mathrm{MSL}\right) . H_{s}$ has the largest influence on the navigation because it is decisive for the frequency of the closure of the barrier. Therefore it should be as high as possible. If $H_{s}$ is raised to 4.0 $\mathrm{m} \mathrm{MSL}$, the frequency of the closure of the port will be reduced to once every 141 years in 2050 and once every 19 years in 2100 . Though the value of $4.0 \mathrm{~m}$ MSL is the highest accepted value for $H_{s}$ as can be seen in Figure 14, it is better to lower the value when the flood safety is at stake.

Further improvements in the study are necessary, especially to give absolute answers to the area under investigation. These improvements are as follows:

(1) The uncertainty in Equal Level Curves and in the statistic analysis of extreme North Sea level will be investigated.

(2) Instead of the Equal Level Curves approach, a more advanced numerical hydrodynamic model should be applied.

(3) Both the sea level and Rhine discharge are not a constant peak value of a certain duration. In this research a semi-unsteady sea level boundary condition seems to be an overestimation. A design hydrograph of the sea level at Hook of Holland is preferred. The sea level consists of several variables like the wind set-up and the astronomical tide; the former occurs randomly and the other occurs deterministically. The phase difference between them is statistically important. In other words, an improved probability analysis of the hydraulic boundary conditions is required. 
(4) Considering the effects of the control parameters in the operation in an integrated manner, constraints on other objectives such as navigation and fresh water supply will influence the parameters. Moreover, instead of one barrier in the mouth of a simplified estuary, there are several barriers and flood gates in the Rhine delta, with different operational controls. All these barriers and other hydraulic structures define a whole system, where an advanced model predictive controller should be applied $[24,25]$.

\section{References}

1. Rosenzweig, C.; Solecki, W.D.; Blake, R.; Bowman, M.; Faris, C.; Gornitz, V.; Horton, R.; Jacob, K.; LeBlanc, A.; Leichenko, R. Developing coastal adaptation to climate change in the New York City infrastructure-shed: Process, approach, tools, and strategies. Clim. Chang. 2011, 106, 93-127.

2. Jonkman, S.N.; Kelman, I. Deaths during the 1953 North Sea storm surge. In: Proceedings of the Solutions to Coastal Disasters Conference, American Society for Civil Engineers, Charleston, VA, USA, 8-11 May 2005; pp.749-758.

3. Van Dantzig, D. Economic decision problems for flood prevention. J. Econom. Soc. 1956, 276-287.

4. Vergeer, G.J.H. Probabilistic Design of Flood Defences; Report 141; Centre for Civil Engineering Research and Codes (CUR): Gouda, The Netherlands, 1990.

5. Van der Made, J.W. Design levels in the transition zone between the tidal reach and the river regime reach. Hydrol. Deltas 1969, 2, 257-272.

6. Jorigny, M.; Diermanse, F.; Hassan, R.; van Gelder, P. Correlation analysis of water levels along Dike-Ring areas. In Proceedings of Computational Methods in Water Resources, Book Series: Developments in Water Science; Hassanizadeh, S.M., Schotting, R.J., Gray W.G., Pinder G.F., Ed.; Elsevier : Amsterdam, The Netherlands, 2002; Volume 47, pp. 1677-1684.

7. Vrijling, J.K.; Gelder, P.H.A.J.M. Probabilistic Design in Hydraulic Engineering; Delft University of Technology: Delft, The Netherlands, 1996; Volume III, pp. 16-27.

8. Van den Hurk, B.; Klein Tank, A.; Lenderink, G.; van Ulden, A.; van Oldenborgh, G.J.; Katsman, C.; van den Brink, H.; Keller, F.; Bessembinder, J.; Burgers, G. KNMI Climate Change Scenarios 2006 for The Netherlands; WR-2006-01; KNMI: De Bilt, The Netherland, 2006.

9. Engel, H. The flood events of 1993/1994 and 1995 in the Rhine River basin. In Proceedings of Destructive Water: Water-Caused Natural Disasters, their Abatement and Control, Anaheim, CA, USA, June 1996; IAHS: Rennes, France, 1997; International Association of Hydrological Sciences Publications No. 239; pp. 21-32.

10. Chbab, E.H. How extreme were the 1995 flood waves on the rivers Rhine and Meuse? Phys. Chem. Earth 1995, 20, 455-458.

11. Berger, H. Hydraulic boundary conditions in the Netherlands, at present and in future. Extrem. Hydrol. Event. New Concept. Secur. 2007, 78, 409-416.

12. Tol, R.S.J.; van der Grijp, N.; Olsthoorn, A.A.; van der Werff, P.E. Adapting to climate: A case study on riverine flood risks in the Netherlands. Risk Anal. 2003, 23, 575-583. 
13. Katsman, C.A.; Sterl, A.; Beersma, J.; van den Brink, H.; Church, J.; Hazeleger, W.; Kopp, R.; Kroon, D.; Kwadijk, J.; Lammersen, R. Exploring high-end scenarios for local sea level rise to develop flood protection strategies for a low-lying delta-The Netherlands as an example. Clim. Chang. 2011, 109, 617-645.

14. Deltacommissie. Working Together with Water. A Living Land Builds for its Future. Findings of the Deltacommissie 2008; Technical Report; Hollandia Printing: Den Haag, The Netherlands, 2008.

15. Bol, R. Operation of the 'Maeslant Barrie': (storm surge barrier in the Rotterdam New Waterway). In Flooding and Environmental Challenges for Venice and Its Lagoon: State of Knowledge; Fletcher, C.A., Spencer, T., Eds.; Cambridge University Press: Cambridge, UK, 2005 ; p. 311.

16. Vrijling, J.K.; Bruinsma, J. Hydraulic Boundary Conditions. Hydraulic Aspects of Coastal Structures; Delft University Press: Delft, the Netherlands, 1980; Volume 1, pp. 109-133.

17. Mann, H.B. Nonparametric tests against trend. J. Econom. Soc. 1945, 13, 245-259.

18. Kendall, M.G. Rank Correlation Measures; Charles Griffin: London, UK, 1975; p. 202.

19. Lehmann, E.L. Nonparametric Statistical Methods Based on Ranks; Holden-Day: San Francisco, CA, USA, 1975.

20. Sneyers, R. On the Statistical Analysis of Series of Observations; World Meteorological Organisation: Geneva, Switzerland, 1990; Volume 415.

21. Wall, F.J. Statistical Data Analysis Handbook; McGraw-Hill: New York, NY, USA, 1986.

22. Van Gelder, P.H.A.J.M. Statistical Methods for the Risk-Based Design of Civil Structures. PhD Dissertation. Delft University of Technology, Delft, The Netherlands, 1999; pp. 185-194.

23. Hawkes, P.J. Joint probability analysis for estimation of extremes. J. Hydraul. Res. 2008, 46, 246-256.

24. Van Overloop, P.J.; Negenborn, R.R.; Schutter, B.D.; Giesen, N.C. Predictive control for national water flow optimization in the Netherlands. Intell. Infrastruct. 2010, 42, 439-461.

25. Van Overloop, P.J. Operational Water Management of the Main Waters in the Netherlands; Technical Report; Delft University of Technology: Delft, the Netherlands, 2009.

(C) 2012 by the authors; licensee MDPI, Basel, Switzerland. This article is an open access article distributed under the terms and conditions of the Creative Commons Attribution license (http://creativecommons.org/licenses/by/3.0/). 